\title{
Contrasting effects of diclofenac and ibuprofen on active imatinib uptake into leukaemic cells
}

\author{
J Wang ${ }^{1,2}$, TP Hughes' ${ }^{1,2,3}$, CH Kok 1,2, VA Saunders', A Frede', K Groot-Obbink', M Osborn ${ }^{1,4}$, AA Somogyi ${ }^{3,5}$, \\ RJ D'Andrea ${ }^{1,2,3,6}$ and DL White*,1,2,3
}

'Department of Hematology, Centre for Cancer Biology/SA Pathology (RAH site), Adelaide, SA, Austarlia; ${ }^{2}$ School of Medicine, University of Adelaide, Adelaide, SA, Austarlia; ${ }^{3}$ Centre for Personalized Cancer Medicine, University of Adelaide, Adelaide, SA, Austarlia; ${ }^{4}$ Women's and Children's Hospital, Adelaide, SA, Austarlia; ${ }^{5}$ Discipline of Pharmacology, University of Adelaide, Adelaide, SA, Austarlia; ${ }^{6}$ The Basil Hetzel Institute for Translational Health Research, Queen Elizabeth Hospital, Adelaide, SA, Austarlia

BACKGROUND: The human organic cation transporter-I (OCT-I) is the primary active protein for imatinib uptake into target BCR-ABL-positive cells. Non-steroidal anti-inflammatory drugs (NSAIDs) are frequently used by chronic myeloid leukaemia (CML) patients on imatinib to manage musculoskeletal complaints.

METHODS: Here we investigated the impact of NSAIDs on functional activity of the OCT-I (OCT-I activity; OA) in CML cells. RESULTS: Although ten of twelve NSAIDs tested had no significant impact on OA $(P>0.05)$, we observed increased $O A(27 \%$ increase in $\mathrm{K} 562 ; 22 \%$ increase in KU8I2 cells, $P<0.05)$ and reduced IC50 imatinib when treated with diclofenac. Co-incubation with imatinib and diclofenac resulted in a significantly lower viable cell number compared with imatinib alone. In contrast, ibuprofen led to a significant decrease in $\mathrm{OA}$, an increase in $1 \mathrm{C} 50^{\text {imatinib }}$ and thus reduced the cytotoxicity of imatinib. In primary CML samples, diclofenac significantly increased OA, particularly in patients with low OA ( $<4$ ng per 200000 cells), and significantly decreased IC50 imatinib. Ibuprofen induced significant decreases in OA in CML samples and healthy donors.

CONCLUSION: On the basis of the expected impact of these two drugs on OA, ibuprofen should be avoided in combination with imatinib. Further studies are warranted regarding the potential benefit of diclofenac to improve OA in a clinical setting.

British Journal of Cancer (2012) I 06, 1772-1778. doi:I0.1038/bjc.2012.173 www.bjcancer.com

Published online 24 April 2012

(c) 2012 Cancer Research UK

Keywords: CML; OCT-I; drug-drug interaction; NSAIDs; imatinib

Imatinib mesylate is a rationally-designed inhibitor of BCR-ABL currently used as first-line treatment for chronic phase chronic myeloid leukaemia (CP-CML). According to the 7-year update of IRIS (International Randomized Study of Interferon and STI571), patients treated with imatinib (STI571) achieved an overall event-free survival of $81 \%$ and transformation-free survival (to accelerated phase/blast crisis) of 93\% (Hughes et al, 2010). Despite these excellent outcomes, suboptimal response or resistance to imatinib was reported soon after the introduction of imatinib into clinical practice (Gorre et al, 2001; Shah et al, 2002).

Although the presence of mutations within the kinase domain of $\mathrm{BCR}-\mathrm{ABL}$ is widely accepted as the most common reason for secondary imatinib resistance (Gorre et al, 2001; Hughes et al, 2006), the underlying cause of primary resistance is less well characterised. The human organic cation transporter-1 (OCT-1) has been identified as the major transporter responsible for imatinib uptake in CML cells (Thomas et al, 2004). We have demonstrated that low functional activity of the OCT-1 protein (OCT-1 activity; OA) measured at the time of diagnosis, results in reduced imatinib-mediated in vitro tyrosine kinase inhibition

* Correspondence: Associate Professor DL White;

E-mail: Deborah.White@health.sa.gov.au

Received II January 2012; revised 23 March 2012; accepted 30 March 2012; published online 24 April 2012
(White et al, 2005) and is associated with a poor outcome in CP-CML patients receiving imatinib therapy (White et al, 2007b, 2010). In some patients the negative impact of a low OA may be partially overcome by escalating imatinib dosage where tolerated (Hughes et al, 2008; White and Hughes, 2012). However, clinical experience has demonstrated that increasing imatinib dose is related to higher rates of adverse events and may lead to dosage interruptions or cessation (Cortes et al, 2010).

Several commonly prescribed drugs have been identified as substrates or inhibitors of OCT-1, thus, the contribution of OCT-1 to drug-drug interactions (DDI) has been reported recently in several pharmacokinetic studies (Kindla et al, 2009; Fahrmayr et al, 2010). Most of these studies used cell lines stably expressing OCT-1, with 1-methyl-4-phenylpyridinium $(\mathrm{MPP}+)$ and metformin as test compounds. In MDCKII-OCT-1 cells, OCT-1 mediated $\mathrm{MPP}+$ and metformin uptake were inhibited by oral anti-diabetic drugs, rosiglitazone and repaglinide (Bachmakov et al, 2008). Antiretroviral drugs for HIV treatment and cardiovascular drugs have been found to inhibit OCT-1 mediated MPP + uptake in transformed HEK293 cells expressing OCT-1 and in primary hepatocytes (Jung et al, 2008; Umehara et al, 2008). Although there is accumulating evidence regarding OCT-1-mediated DDI, few studies have investigated the effect of DDI on OCT-1 mediated imatinib uptake. Minematsu and Giacomini (2011) reported the selective and potent inhibitory effect of imatinib on ${ }^{14} \mathrm{C}$-metformin uptake using HEK293 cells stably expressing OCT-1. However, the 
DDI involving imatinib and OCT-1 in CML cells has not been fully assessed to date.

Non-steroidal anti-inflammatory drugs (NSAIDs) are a class of structurally diverse drugs that effectively inhibit cyclooxygenases (COX-1 and COX-2) (Ulrich et al, 2006). Non-steroidal antiinflammatory drugs are very commonly used for treatment of arthritic conditions and different types and severities of inflammation. There has been abundant evidence of DDI between NSAIDs and other co-administrated drugs, which may prolong the plasma elimination and lead to various side effects such as liver damage (Bjorkman, 1998), kidney dysfunction (Perneger et al, 1994), and aggravation of cardiovascular diseases (Farooq et al, 2008). Recently, several studies suggested that the transporter responsible for the renal uptake and secretion for NSAIDs is the human organic anion transporter-1 (OAT-1) (Apiwattanakul et al, 1999; Nozaki et al, 2004; Honjo et al, 2011). At clinically relevant concentrations, NSAIDs efficiently inhibit hOAT-1-mediated transport of adefovir in a cell line stably expressing hOAT-1 (Mulato et al, 2000). Although it has been reported that NSAIDs are not substrates of OCT transporters (Khamdang et al, 2002), NSAIDs such as diclofenac, ibuprofen, indomethacin and sulindac have been demonstrated to significantly inhibit OCT-1-mediated TEA uptake at the concentration of $0.5 \mathrm{~mm}$ in transfected $\mathrm{S}_{2}$ cells expressing hOCT-1 (Khamdang et al, 2002). As about one-quarter to one-half of CML patients on imatinib develop musculoskeletal complaints (muscle cramps, myalgia, arthralgia), which may need to be managed with NSAIDs (Deininger et al, 2003), it is of particular relevance to investigate the effect on imatinib uptake of NSAIDs. An understanding of the effects that these drugs may have on imatinib influx in BCR-ABL-positive cells is of significant value for clinical practice.

In this study we performed a systematic functional analysis of the effects of 12 commonly used NSAIDs on imatinib uptake via OCT-1 in CML cell lines, and de novo CP-CML patients' cells. As previous studies have demonstrated that the influx of nilotinib and dasatinib are not mediated by OCT-1 (White et al, 2006; Giannoudis et al, 2008; Hiwase et al, 2008), imatinib was selected as the only relevant substrate for the OCT-1 transporter in the current study. Our data demonstrates that NSAIDs result in varying effects on OA. Among them two widely used NSAIDs, diclofenac and ibuprofen, resulted in significant change in the OA, kinase inhibition and imatinib efficacy in vitro at clinically achievable total plasma concentrations $(10 \mu \mathrm{M}$ for diclofenac and $130 \mu \mathrm{m}$ for ibuprofen) (Siu et al, 2000; Juhlin et al, 2004; Bramlage and Goldis, 2008). Thus, their concomitant use with imatinib in CML patients warrants further experimental and clinical examination

\section{MATERIALS AND METHODS}

\section{Cell lines}

Human BCR-ABL-positive K562 and KU812 CML cell lines were obtained from the American Type Culture Collection (ATCC, Manassas, VI, USA). All cell lines were cultured in a $37^{\circ} \mathrm{C}$ humidified atmosphere of $5 \% \mathrm{CO}_{2}$ in RPMI-1640 media (SigmaAldrich, St. Louis, MO, USA) supplemented with $10 \%$ foetal bovine serum (JRH Biosciences, Lenexa, KS, USA), 2 mm L-glutamine (SAFC Biosciences, Lenexa, KS, USA) and $100 \mathrm{U} \mathrm{ml}^{-1}$ penicillin G/streptomycin (Sigma-Aldrich).

\section{Patient samples}

Blood was obtained from de novo CP-CML patients, before the commencement of imatinib therapy. Normal blood was obtained from healthy volunteers. All blood samples were collected with informed consent in accordance with the Declaration of Helsinki. Mononuclear cells (MNCs) were isolated from blood using
Lymphoprep (Axis Shield, Oslo, Norway) density gradient centrifugation. Experiments were performed on fresh or frozen cells. Use of clinical trial patients' samples (TIDELI) was approved by the Royal Adelaide Hospital Research Ethics Committee (Novartis protocol No: CST15710106).

\section{Drugs}

Imatinib mesylate, together with labelled imatinib ([ $\left.\left.{ }^{14} \mathrm{C}\right]-\mathrm{STI} 571\right)$ were kindly provided by Novartis Pharmaceuticals (Basel, Switzerland). Celecoxib and rofecoxib were purchased from Toronto Research Chemicals (Ontario, CA, USA). Paracetamol was kindly provided by Professor Andrew A Somogyi, the University of Adelaide (Adelaide, Australia). Other NSAIDs were purchased from Sigma-Aldrich and dissolved as per manufacturer's instructions. For those drugs dissolved in DMSO or ethanol, the final concentration of the solvents ranged from $0.14-0.25 \%(\mathrm{v} /$ $v)$. The concentrations of NSAIDs used in this study were selected according to the concentrations reported to be the maximum plasma concentrations after therapeutic dosing. For those of which the optimal concentrations were unknown, the concentrations commonly chosen in high-throughput cell-based small-molecule screens were used (Supplementary Table 1). The OCT-1 inhibitor prazosin (Sigma-Aldrich) was dissolved in methanol and used at $100 \mu \mathrm{m}$. The final concentration of methanol was $1 \%(\mathrm{v} / \mathrm{v})$.

\section{Radio-labelled drug uptake (IUR) assay and OA assay: assessment of the effects of NSAIDs on OA modulation}

As previously described (White et al, 2007b), the radio-labelled intracellular uptake and retention (IUR) assay measures the intracellular concentration of imatinib achieved and maintained in cells over a 2-hour period. Non-steroidal anti-inflammatory drugs and the potent inhibitor of OCT-1, prazosin were added to the IUR assay simultaneously with radio-labelled imatinib. After incubation, the cellular and aqueous phases were separated and incorporation was determined using a Topcount Microplate Beta Scintillation counter (Canberra Packard, Meriden, CO, USA) following the addition of Microscint20 scintillation fluid (Perkin Elmer, Boston, MA, USA). The OA was determined by calculating the difference of the IUR with or without $100 \mu \mathrm{m}$ prazosin.

\section{IC50 ${ }^{\text {imatinib }}$ assay: assessment of the effects of NSAIDs on tyrosine kinase inhibition}

The IC50 assay was performed as previously described (White et al, 2005), based on the in vitro reduction in the level of phosphorylated Crkl (p-Crkl) as a result of exposure to increasing concentrations of imatinib (ranged from 0 to $100 \mu \mathrm{M}$ ). The percentage of $\mathrm{p}$-Crkl to non-p-Crkl at $0 \mu \mathrm{m}$ imatinib was standardised to $100 \%$, and all other data points were normalised to this value. The IC50 was defined as the concentration of imatinib producing a $50 \%$ decrease in the level of $\mathrm{p}$-Crkl compared with untreated controls. The effects of NSAIDs were determined by comparing the IC50 in the presence and absence of NSAIDs in cell lines and primary patients' material.

Trypan blue exclusion assay: assessment of the effects of NSAIDs on the number of viable cells in the presence of imatinib

After treatment with NSAIDs and various concentrations of imatinib (indicated in the text) for 72 hours, cells were harvested and viable cell numbers were assessed using the trypan blue (Sigma-Aldrich) exclusion method. The number of viable cells was then compared with a control treatment in the absence of NSAIDs. 


\section{RQ-PCR assay: assessment of the effects of NSAIDs on} OCT-1 mRNA levels

The RQ-PCR for transporter mRNA expression was performed as previously described (White et al, 2007b). The cells were harvested after 2-hour incubation with NSAIDs. RNA was then extracted using TRIzol Reagent (Invitrogen, Carlsbad, CA, USA). The sequences for the primers were as follows: OCT-1 forward 5'-CTGAGCTGTACCCCACATTCG-3', OCT-1 reverse 5'-CCAACA CCGCAAACAAAATGA- $3^{\prime}$.

\section{Statistical analyses}

All statistical analyses are indicated where applied and were performed using Sigma Stat Software 3.0 (Systat Software Asia Pacific Ltd, Richmond, CA, USA). The unpaired $t$-test was used to define differences between blank and NSAIDs-treated group, and correlation was performed using the Pearson Product Moment. Data are presented as mean \pm s.e.m. for at least three biological replicates. Differences were considered to be statistically significant when the $P$-value was less than 0.05 .

\section{RESULTS}

\section{Effects of NSAIDs on OA and IC50 ${ }^{\text {imatinib }}$ of BCR-ABL-positive cell lines}

Diverse effects on OA were observed in BCR-ABL positive cell lines (K562 and KU812) in the presence and absence of NSAIDs. Although the majority of NSAIDs selected ( 9 of 12) failed to induce any significant change in OA (Figure $1 \mathrm{~A}$ ), a significant increase in OA was observed in K562 cells treated with either $10 \mu \mathrm{M}$ diclofenac $(27 \%, n=4, P=0.007)$ or $16 \mu \mathrm{M}$ fenbufen $(33 \%, n=9, P=0.006)$, Similarly, a $22 \%$ increase was observed in OA when KU812 cells were treated with $10 \mu \mathrm{M}$ diclofenac $(n=6, P=0.003$, Figure $1 \mathrm{~B})$. Although not significant, incubation with fenbufen resulted in a $21 \%$ increase in OA in KU812 cells $(n=5, P=0.328)$. Surprisingly, and in contrast, the OA was reduced in the presence of ibuprofen ( $48 \%$ of vehicle control in K562, $n=4, P<0.001$, Figure $1 \mathrm{~A} ; 59 \%$ of vehicle control in KU812, $n=6, P<0.001$, Figure 1B). As diclofenac and ibuprofen demonstrated the most significant effect on $\mathrm{OA}$, and as both are commonly used in clinical practice, these drugs were selected for further experimentation.

\section{Effects of diclofenac and ibuprofen on IC50 $0^{\text {imatinib }}$ of BCR-ABL-positive cell lines}

To assess whether the observed divergent alterations in $\mathrm{OA}$ translate into changes in tyrosine kinase inhibition, the IC50 imatinib was examined in K562 and KU812 cells with or without diclofenac or ibuprofen. A significant decrease in the IC50 imatinib was observed in K562 cells when treated with diclofenac (5.7 \pm 0.8 to $3.7 \pm 0.7 \mu \mathrm{M}, P=0.013, n=3$, Figure $2 \mathrm{~A})$. In addition, a similar decrease was observed in the KU812 IC50 ${ }^{\text {imatinib }}$ in the presence of diclofenac ( $3.5 \pm 0.6$ to $2.2 \pm 0.4 \mu \mathrm{M}, P=0.007, n=3$, Figure $2 \mathrm{~B}$ ). In contrast, ibuprofen significantly elevated the IC50 imatinib in K562 and KU812 cells $(5.7 \pm 0.8$ to $8.1 \pm 0.5 \mu \mathrm{M}$ and $3.5 \pm 0.6$ to $6.6 \pm 0.8 \mu \mathrm{M}$, respectively; $P<0.001, n=3$ ).

Effects of diclofenac and ibuprofen on viable cell counts when co-administrated with imatinib and OCT-1 mRNA levels in BCR-ABL-positive cells

To address whether the changes in imatinib intracellular concentration and IC $50^{\text {imatinib }}$ mediated by diclofenac or ibuprofen translate to changes in viable cell number, the trypan blue cell exclusion assay was performed with K562 and KU812 cells in the presence or absence of diclofenac and ibuprofen. After 72 hours

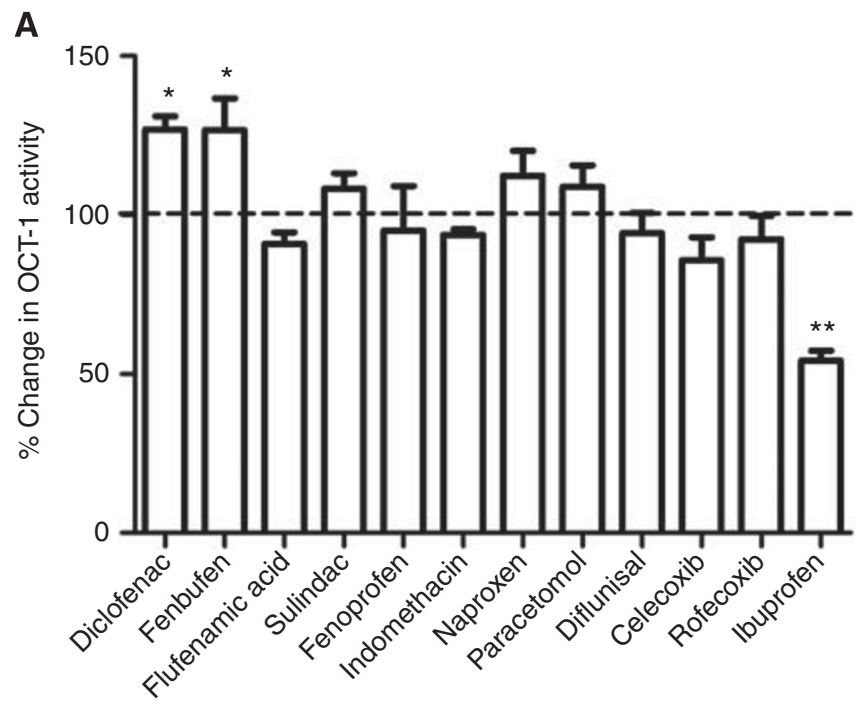

B

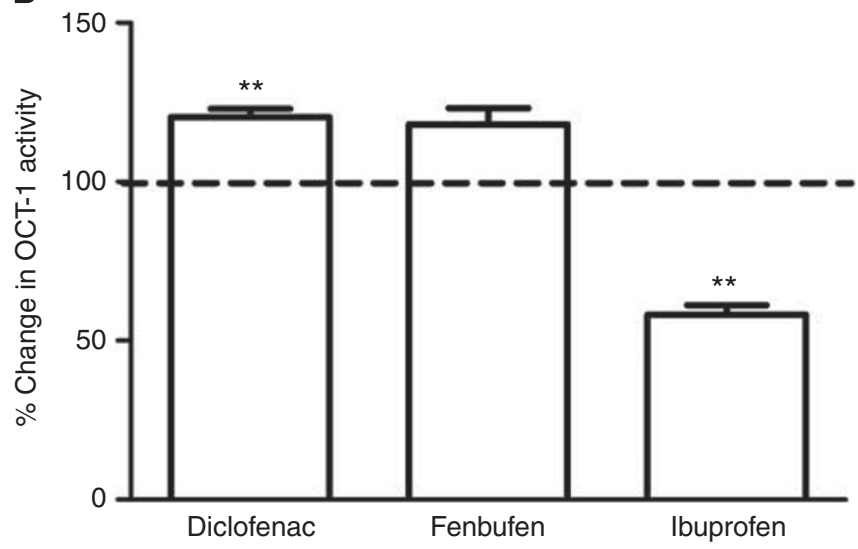

Figure I Non-steroidal anti-inflammatory drugs induce divergent effects on OCT-I activity in BCR-ABL-positive cells. NSAIDs and the potent inhibitor of OCT-I, prazosin, were added to the OCT-I activity assay simultaneously with ${ }^{14} \mathrm{C}$-imatinib. After 2 -hour incubation, the $\mathrm{OA}$ was determined by calculating the difference of the intracellular uptake and retention with or without prazosin. Results (mean \pm s.e.m.) are expressed as percentage of own solvent control, which was set at a value of $100 \%$, for at least three biological replicates. $* P<0.05$ vs control; $* * P<0.00$ I vs control. (A) OCT-I activity in the presence of 12 NSAIDs in K562 cells. (B) OCT-I activity in the presence of $10 \mu \mathrm{M}$ diclofenac, $16 \mu \mathrm{M}$ fenbufen and I $45 \mu \mathrm{m}$ ibuprofen in KU812 cells.

incubation with varying doses of imatinib as shown in Figure 3, KU812 cells are more sensitive to the effects of imatinib than K562 cells. Thus, different doses of imatinib were used in K562 and KU812 cells. At relatively low doses of imatinib $(0.25 \mu \mathrm{m}$ for K562 cells; $0.05 \mu \mathrm{M}$ for KU812 cells), diclofenac resulted in a significantly lower number of viable cells after 72 hours compared with imatinib alone $\left(7.82 \pm 0.56 \times 10^{5} \mathrm{ml}^{-1}\right.$ vs $10.95 \pm 1.01 \times 10^{5} \mathrm{ml}^{-1}$ in $\mathrm{K} 562$ cells: $P=0.021, \quad n=3 ; \quad 5.40 \pm 0.34 \times 10^{5} \mathrm{ml}^{-1}$ vs $8.40 \pm 0.74 \times$ $10^{5} \mathrm{ml}^{-1}$ in KU812 cells: $P=0.019, n=3$, Figures $3 \mathrm{~A}$ and $\mathrm{B}$ ), which is consistent with the observed decrease in IC50 0 imatinib Interestingly, this effect is not due to diclofenac-induced cell death as there was no significant change observed in cell viability in the presence or absence of diclofenac alone.

In contrast, when K562 or KU812 cells were co-incubated with imatinib and ibuprofen there was a significant increase in viable cell number compared with cells treated with imatinib alone $\left(8.16 \pm 1.01 \times 10^{5} \mathrm{ml}^{-1}\right.$ vs $4.88 \pm 0.96 \times 10^{5} \mathrm{ml}^{-1}$ in $\mathrm{K} 562$ cells at $0.5 \mu \mathrm{M}$ of imatinib, $P=0.004, n=3 ; 7.23 \pm 0.78 \times 10^{5} \mathrm{ml}^{-1}$ vs 
A


Figure 2 The IC $50^{\text {imatinib }}$ results in the presence or absence of $10 \mu \mathrm{M}$ diclofenac or I $45 \mu \mathrm{m}$ ibuprofen. The in vitro reduction in the level of $\mathrm{p}-\mathrm{Crkl}$ by imatinib was detected using the IC50 imatinib assay. Cells were incubated with I $0 \mu \mathrm{M}$ diclofenac or I $45 \mu \mathrm{M}$ ibuprofen and increasing concentrations of imatinib for 2 hours. The percentage of $\mathrm{p}$-Crkl to non-p-Crkl at $0 \mu \mathrm{M}$ imatinib was standardised to $100 \%$, and all other data points were normalised about this value. The IC50 was defined as the concentration of imatinib producing a $50 \%$ decrease in the level of $\mathrm{p}$-Crkl compared with untreated controls. Error bars represent mean \pm s.e.m. for three biological replicates. $* P<0.05$ vs control; $* * P<0.00$ I vs control. The cumulative results $(\mathbf{A})$ in $\mathrm{K} 562$ cells $(\mathbf{B})$ in $\mathrm{KU} 8 \mathrm{I} 2$ cells.

$4.97 \pm 0.47 \times 10^{5} \mathrm{ml}^{-1}$ in KU812 cells at $0.1 \mu \mathrm{M}$ of imatinib, $P=0.002, n=3$, Figures $3 \mathrm{~A}$ and $\mathrm{B}$ ).

To determine whether the level of OCT-1 mRNA was affected by the presence of NSAIDs OCT1 transcript levels were analysed following a 2-hour incubation in the presence and absence of NSAIDs in both K562 and KU812 cells. There was no significant change in the level of OCT-1 mRNA with diclofenac or ibuprofen over the 2-hour period (data not shown), suggesting that these NSAIDs function via a post-transcriptional mechanism.

\section{Effects of diclofenac and ibuprofen on the OA of primary cells}

Our previous TIDEL study in newly diagnosed CML patients receiving imatinib at $600 \mathrm{mg}$ per day has described the link between $\mathrm{OA}$ and achievement of optimal or sub-optimal molecular response. The percentage of patients with high $\mathrm{OA}$ achieving major molecular response (MMR) by 24 months was significantly greater than that of patients with low OA ( $85 \%$ vs $45 \%, P=0.004)$ (White et al, 2007b). Dividing the OA groups further into quartiles, patients with OA in the lowest quartile (Q1, OA $<4$ ng per 200000 cells) have a significantly poorer response to imatinib treatment than those in higher quartiles (White et al, 2010). To examine the effect of both drugs on OA in primary CML samples, OA of MNCs
A
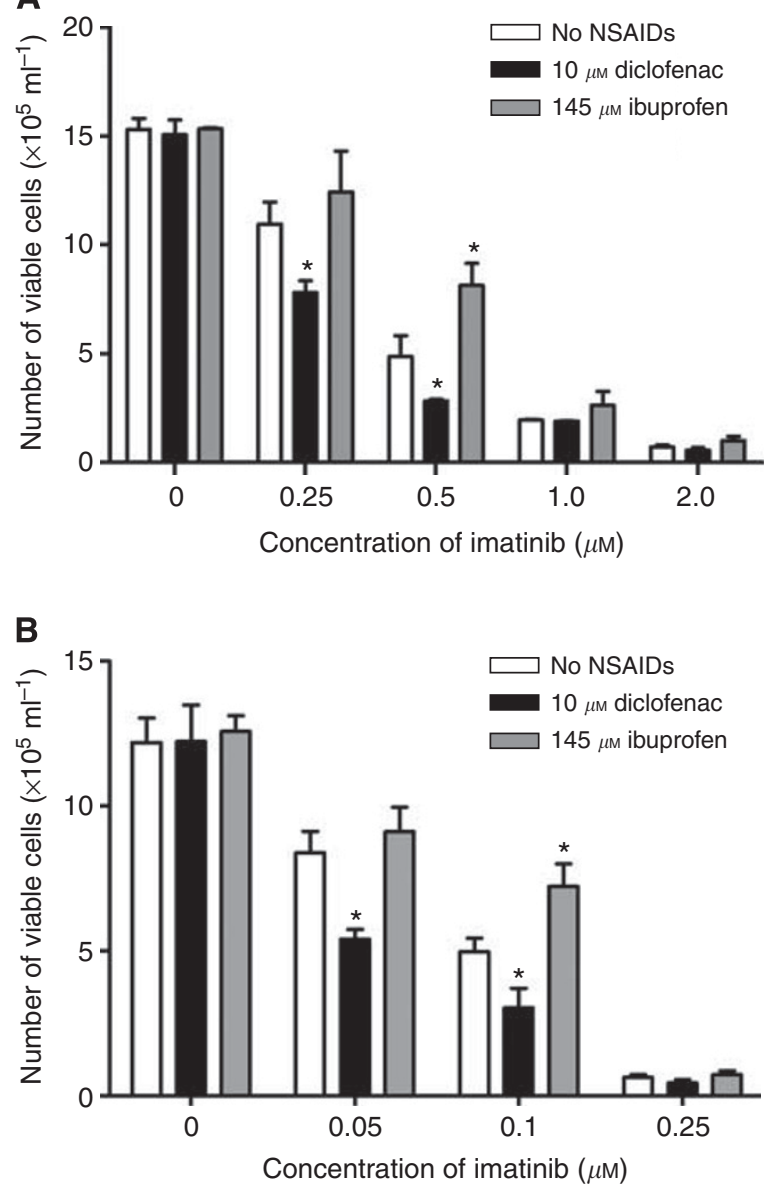

Figure 3 The effects of diclofenac and ibuprofen on the number of viable cells after 72 hours co-incubation with imatinib. The number of viable cells was determined using the trypan blue exclusion method after treatment with NSAIDs and imatinib for 72 hours. $10 \mu \mathrm{M}$ diclofenac coadministered with imatinib induced a significantly lower viable cell number compared with imatinib alone. Conversely, the viable cell numbers were significantly increased by $145 \mu \mathrm{M}$ ibuprofen with imatinib, especially at relatively higher concentration of imatinib. The results (mean \pm s.e.m) are expressed as the viable cell number determined by trypan blue exclusion assay of three biological replicates. ${ }^{*} P<0.05$ versus control. $(\mathbf{A})$ in $\mathrm{K} 562$ cells $(n=3)(\mathbf{B})$ in KU8I2 cells $(n=3)$.

isolated from TIDEL patients were assessed in the presence or absence of $10 \mu \mathrm{m}$ diclofenac or $145 \mu \mathrm{m}$ ibuprofen.

We then compared the effect of diclofenac on MNCs from patients with OA in Q1 (OA less than 4 ng per 200000 cells) with the effect observed in patients with OA greater than $4 \mathrm{ng}$ per 200000 cells. After treatment with diclofenac, the OA was increased in $93 \%$ of the Q1 patients' samples tested. The median OA in Q1 patients rose from 1.39 to $4.17 \mathrm{ng}$ per 200000 cells $(n=29$, $P<0.001)$. Notably, as the result of this increase, 15 of 29 cases (51.7\%) moved from Q1 to a higher OA quartile group (Figure 4A). However, for patients with higher basal $\mathrm{OA}$ value, treatment with diclofenac did not lead to a significant increase in OA (median OA in the absence or presence of diclofenac: $5.49 \mathrm{ng} / 200,000$ cells $v s$ 5.92 ng per 200000 cells, $n=21, P=0.714$, Figure 4B). The different effect of diclofenac between quartiles indicated that the increase in OA mediated by diclofenac was largely confined to patients with low OA rather than in patients with higher OA.

In MNCs treated with ibuprofen, a consistent inhibitory effect ( $41 \%$ reduction in $\mathrm{OA}$ ) was observed in all 12 cases tested (Figure $4 \mathrm{C})$. The average $\mathrm{OA}$ in these 12 samples $(7.53 \pm 0.82 \mathrm{ng}$ per 
A

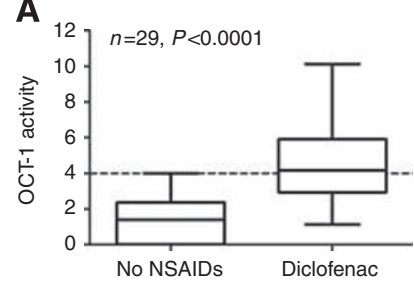

B



C

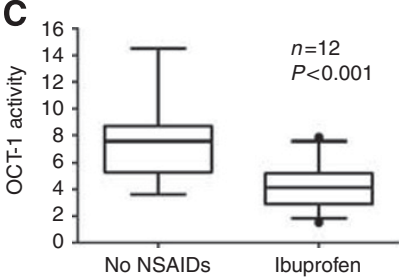

Figure 4 The effects of diclofenac or ibuprofen on $\mathrm{OA}$ in primary MNCs. OCT-I activity assays were performed with fresh or frozen MNCs isolated from the blood of newly diagnosed patients with CML. Box-plots display the median value, the minimum and maximum value of $\mathrm{OA}$. (A) $10 \mu \mathrm{m}$ diclofenac increased $\mathrm{OA}$ in patients with basal $\mathrm{OA}$ less than $4 \mathrm{ng}$ per 200000 cells $(n=29)$. (B) No significant increase was observed in patients with basal OA greater than 4 ng per 200000 cells $(n=21)$. (C) Decreased $\mathrm{OA}$ in MNCs from de-novo CP-CML patients were observed after treatment of $145 \mu \mathrm{M}$ ibuprofen $(n=12)$. (D) lbuprofen downregulated OA in healthy donors $(n=6)$.

200000 cells, range 3.53-14.52) was significantly reduced $(4.30 \pm 0.52 \mathrm{ng}$ per 200000 cells, range $1.53-7.85, P<0.001)$ after the treatment with ibuprofen.

In addition, we have examined the effect of diclofenac $(n=10)$ or ibuprofen $(n=6)$ on MNCs collected from normal individuals. Diclofenac did not result in a significant change in OA (data not shown), however, a $50 \%$ decrease in OA was observed following ibuprofen treatment (OA before treatment: $3.70 \pm 0.45 \mathrm{ng}$ per 200000 cells, range $2.21-4.89$; OA post treatment: $1.83 \pm 0.26 \mathrm{ng}$ per 200000 cells, range 1.41-2.82, $P<0.001$, Figure 4D).

\section{The impact of diclofenac on the IC $50^{\text {imatinib }}$ in primary cells}

As diclofenac resulted in a significant increase in OA in MNCs of CP-CML patients, its impact on in vitro kinase inhibition was determined in 9 de novo CP-CML patients. Patients were chosen based on the availability of sufficient fresh blood cells for this analysis, not on the basis of OA. The median IC $50^{\text {imatinib }}$ of this group was $1.2 \mu \mathrm{M}$ (range $0.5-1.7 \mu \mathrm{M}$ ). A significant reduction was observed when diclofenac was added (median IC50 imatinib reduced to $0.75 \mu \mathrm{M}$, range $0.25-1.15 \mu \mathrm{M}, P=0.018$, Figure 5).

\section{DISCUSSION}

The interaction between NSAIDs and OCT-1 remains unknown but has significant potential to impact response to imatinib. Here we investigate the potential involvement of NSAIDs in targeted cancer therapy where transport of the anti-leukaemic drug into leukaemic cells has a major role in patient response. Twelve NSAIDs were selected in this study; including the commonly used diclofenac, ibuprofen, naproxen, and celecoxib. Their effects on OCT-1 were first validated in assays of imatinib uptake (IUR). Two NSAIDs with the most significant effects on OA, diclofenac and ibuprofen, were then chosen for IC $50^{\text {imatinib }}$ and cell proliferation assays using CML cell lines.

As OCT-1 is the major active influx transporter for imatinib, OA is a strong predictor of response to imatinib treatment in de novo

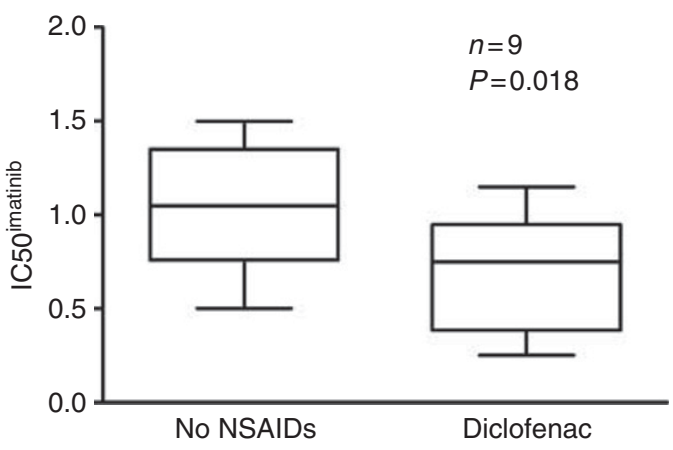

Figure 5 The impact of diclofenac on the IC50 imatinib in primary MNCs from de-novo CP-CML patients. Mononuclear cells samples from 9 de-novo CP-CML patients were incubated with $10 \mu \mathrm{M}$ diclofenac and increasing concentrations of imatinib for 2 hours. The percentage of $p$-Crkl to non-p$\mathrm{Crkl}$ at $0 \mu \mathrm{M}$ imatinib was standardised to $100 \%$. All other data points were normalised about this value. The IC50 was defined as the concentration of imatinib achieving a 50\% decrease of p-Crkl compared with no imatinib controls. When there were sufficient MNCs, analysis was performed in duplicate. Box-plots display the median value, the minimum and maximum value of $\bigcirc A$

CML patients (White et al, 2005, 2007a). Here our data demonstrated that $\mathrm{OA}$ was increased in BCR-ABL-positive cell lines (K562 and KU812) by diclofenac. Importantly, this increase in $\mathrm{OA}$ translated to a significant increase in BCR-ABL kinase inhibition as demonstrated by a reduction in the IC $50^{\text {imatinib }}$ in both cell lines. This finding also highlights, in line with our previous studies (White et al, 2007b), the correlation between

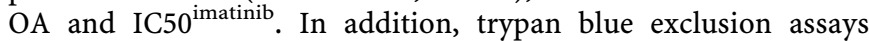
provided further evidence that by increasing functional $\mathrm{OA}$ and tyrosine kinase inhibition, diclofenac in combination with imatinib results in a significant reduction in viable cell numbers.

Interestingly, the effect of diclofenac was also observed in CML patients' samples. In $93 \%$ of MNCs samples from CML patients with basal OA less than $4 \mathrm{ng}$ per 200000 cells (Q1), we demonstrated a significant increase in $\mathrm{OA}$ in the presence of diclofenac at clinically relevant concentrations. Importantly, $51.7 \%$ of Q1 cases tested increased from Q1 to higher quartiles. From a clinical perspective, this increase is of greater significance for the Q1 patients who have a particularly poor outcome on standard imatinib therapy. On the basis of the TIDEL data this may significantly increase the probability of these patients achieving a MMR, and significantly reduce the risk of suboptimal response or imatinib failure (White et al, 2010). However, diclofenac did not significantly increase $\mathrm{OA}$ in cells from patients with higher OA. This differential effect of diclofenac in patients with higher OA suggested that this population may not be targeted as well as Q1 by diclofenac intervention.

When applied to MNCs from healthy donors, diclofenac did not mediate the same effect as seen in CML patients, implicating a role for BCR-ABL or disease-related processes in this interaction. These findings raise the possibility that combination therapy with imatinib plus diclofenac may be more effective than imatinib alone, although not adding greatly to the toxicity of the therapy. Importantly from a clinical perspective, this may translate to an increase in the probability of patients with low $\mathrm{OA}$ achieving a MMR, and a significantly reduced risk of suboptimal response or imatinib failure. In addition, this strategy may also benefit patients with low OA by allowing for a lower/standard dosage of imatinib ( $400 \mathrm{mg}$ per day) without adding greatly to the toxicity commonly observed when higher doses of imatinib are used $(600$ or $800 \mathrm{mg}$ per day). However, extrapolations of in vitro effects to in vivo effects and clinical response will require careful validation.

Another interesting finding in this study is that NSAIDs can exhibit divergent effects on OA in CML cell lines. Although all 
NSAIDs have antipyretic, analgesic, and anti-inflammatory properties, there are several important differences in their activities that are mostly due to their affinity towards COX enzyme isoforms: COX-1 and COX-2. In CML, it was reported that expression of COX-2 was significantly higher in CML than in healthy volunteers and the increasing levels of COX-2 were significantly associated with shorter survival (Giles et al, 2002). Therefore several studies have been conducted to investigate the role of COX-2 in imatinib resistance and the use of COX-2 inhibitors as an alternative therapy. It has been reported that celecoxib, a COX-2 inhibitor, reduced cell growth with arrest of the cell cycle at G0/G1 phase and induction of apoptosis by inhibiting NF- $\kappa \mathrm{B}$ activation in K562 cells (Subhashini et al, 2005). In imatinib-resistant K562 (IR-K562) cells, over-expression of COX-2 and MDR-1 were observed and in addition, celecoxib could induce cell apoptosis by inhibiting COX2 and MDR-1 (Arunasree et al, 2008), probably through the PGE2cAMP-PKC-mediated pathway (Kalle et al, 2010). However, we did not observe any universal effect among COX-2 inhibitors in this study. Although sharing similar COX-2 selectivity with diclofenac (Rich, 2001), celecoxib, as well as another more potent selective COX-2 inhibitor, rofecoxib, had no significant impact on imatinib uptake via OCT-1 in K562 or KU812 cells. This finding suggests that COX-2 inhibitors are unlikely to be the critical mediator of the interaction between OCT-1 and diclofenac observed in this study.

Unexpectedly, although diclofenac increased OA significantly, ibuprofen significantly decreased the OA in both K562 and KU812 cells. This effect on OA translated into an increase in IC $50^{\text {imatinib }}$ and cell growth in the presence of imatinib. Given the common administration and over-the-counter access of ibuprofen, this finding is likely to be of significant clinical relevance. Unlike diclofenac, the effect of ibuprofen is also observed in normal cells to the same extent as leukaemic cells, suggesting that the mechanisms of these two interactions are different.

The various effects of NSAIDs on OCT-1-mediated DDI is in contrast with a previous study reporting that diclofenac, ibuprofen, indomethacin and sulindac could all significantly inhibit OCT1-mediated TEA uptake (Khamdang et al, 2002). However, it should be noted that the concentration of NSAIDs used in that study $(0.5 \mu \mathrm{M})$ was much higher than the concentrations used in our study. Given that the mean maximum plasma concentration (Cmax) of diclofenac after a single dose of $50 \mathrm{mg}$ in healthy volunteers is $5 \mu \mathrm{m}$ (Siu et al, 2000; Juhlin et al, 2004), the dose used in this study is more relevant to the clinical setting. Similarly, the concentration of ibuprofen used here $(145 \mu \mathrm{M}$, equal to $30 \mu \mathrm{g} \mathrm{ml}^{-1}$ ) is determined according to the clinically achievable level $\left(\mathrm{Cmax}=37 \mu \mathrm{g} \mathrm{ml}^{-1}\right.$, after $400 \mathrm{mg}$ single administration in healthy volunteers) (Bramlage and Goldis, 2008). Although this concentration is also lower than $0.5 \mu \mathrm{M}$, it is still much higher (up to 20-fold) than other NSAIDs selected in the current work. As it has been shown that NSAIDs are not substrates of OCT transporters (Khamdang et al, 2002), it is unlikely that ibuprofen inhibits imatinib uptake by competing for OCT-1. Molecular structural analysis is necessary to further understand the interaction between ibuprofen and imatinib at the binding site of OCT-1.

We did not observe changes in OCT-1 mRNA that could explain the differences in imatinib uptake and intracellular level. Thus, the major cause of increased OA and kinase inhibition in these shortterm assays may be from the effects of these drugs on the post-transcriptional regulation of OCT-1. So far a number of posttranscriptional mechanisms for OCT-1 modulation have been reported, including protein kinase A phosphorylation sites which can affect transporter regulation and substrate specificity (Ciarimboli et al, 2004; Ciarimboli et al, 2005; Holle et al, 2011). Other regulatory pathways identified in transfected Chinese hamster ovary cells include p56 ${ }^{\text {lck }}$, calmodulin and the calmodulin-dependent protein kinase II (Ciarimboli et al, 2004). However, the mechanisms underlining OCT-1 regulation in leukaemic cells remains unknown. Further studies are required to establish whether these drugs affect these pathways or impact on OCT-1 transcript or protein levels over longer time periods, or with constant in vivo exposure as would occur clinically. Better understanding of OCT-1 regulation and imatinib influx may lead to additional approaches and drug candidates to enhance imatinib efficacy in CML.

In conclusion, this study provides evidence for interactions between selected NSAIDs and imatinib that directly impact on leukaemic cell response, suggesting that these drugs have the potential to impact significantly on CML patient outcome. The effect of NSAIDs on OA was highly selective suggesting that the mechanism is not related to direct COX inhibition and further studies are required to establish the nature of the interaction in leukaemic cells. Although drugs such as diclofenac may have a positive influence on imatinib efficacy, this is in contrast to the effect seen with ibuprofen suggesting caution is required when administrating NSAIDs to CML patients on imatinib treatment.

\section{ACKNOWLEDGEMENTS}

This work was supported by funding from the Leukemia \& Lymphoma Society (USA). We acknowledge the support of Novartis Pharmaceuticals for providing the Imatinib mesylate, together with labeled imatinib $\left(\left[{ }^{14} \mathrm{C}\right]-\mathrm{STI} 571\right)$.

Supplementary Information accompanies the paper on British Journal of Cancer website (http://www.nature.com/bjc)

\section{REFERENCES}

Apiwattanakul N, Sekine T, Chairoungdua A, Kanai Y, Nakajima N, Sophasan S, Endou H (1999) Transport properties of nonsteroidal anti-inflammatory drugs by organic anion transporter 1 expressed in Xenopus laevis oocytes. Mol Pharmacol 55(5): 847-854

Arunasree KM, Roy KR, Anilkumar K, Aparna A, Reddy GV, Reddanna P (2008) Imatinib-resistant K562 cells are more sensitive to celecoxib, a selective COX-2 inhibitor: Role of COX-2 and MDR-1. Leuk Res 32(6): 855-864

Bachmakov I, Glaeser H, Fromm MF, Konig J (2008) Interaction of oral antidiabetic drugs with hepatic uptake transporters: focus on organic anion transporting polypeptides and organic cation transporter 1 . Diabetes 57(6): 1463-1469

Bjorkman D (1998) Nonsteroidal anti-inflammatory drug-associated toxicity of the liver, lower gastrointestinal tract, and esophagus. Am J Med 105(5 A): 17S-21S

Bramlage P, Goldis A (2008) Bioequivalence study of three ibuprofen formulations after single dose administration in healthy volunteers. BMC Pharmacol 8: 1471-1487

Ciarimboli G, Koepsell H, Iordanova M, Gorboulev V, Dürner B, Lang D, Edemir B, Schröter R, Van Le T, Schlatter E (2005) Individual PKC-phosphorylation sites in organic cation transporter 1 determine substrate selectivity and transport regulation. J Am Soc Nephrol 16(6): 1562-1570

Ciarimboli G, Struwe K, Arndt P, Gorboulev V, Koepsell H, Schlatter E, Hirsch JR (2004) Regulation of the human organic cation transporter hOCT1. J Cell Physiol 201(3): 420-428

Cortes JE, Baccarani M, Guilhot F, Druker BJ, Branford S, Kim DW, Pane F, Pasquini R, Goldberg SL, Kalaycio M, Moiraghi B, Rowe JM, Tothova E, De Souza C, Rudoltz M, Yu R, Krahnke T, Kantarjian HM, Radich JP, Hughes TP (2010) Phase III, randomized, open-label study of daily imatinib mesylate $400 \mathrm{mg}$ versus $800 \mathrm{mg}$ in patients with newly diagnosed, previously untreated chronic myeloid leukemia in chronic phase using molecular end points: tyrosine kinase inhibitor optimization and selectivity study. J Clin Oncol 28(3): $424-430$ 
Deininger MWN, O’Brien SG, Ford JM, Druker BJ (2003) Practical management of patients with chronic myeloid leukemia receiving imatinib. J Clin Oncol 21(8): 1637-1647

Fahrmayr C, Fromm MF, König J (2010) Hepatic OATP and OCT uptake transporters: Their role for drug-drug interactions and pharmacogenetic aspects. Drug Metab Rev 42(3): 380-401

Farooq M, Haq I, Qureshi AS (2008) Cardiovascular risks of COX inhibition: Current perspectives. Expert Opin Pharmacother 9(8): 1311-1319

Giannoudis A, Davies A, Lucas CM, Harris RJ, Pirmohamed M, Clark RE (2008) Effective dasatinib uptake may occur without human organic cation transporter 1 (hOCT1): implications for the treatment of imatinibresistant chronic myeloid leukemia. Blood 112(8): 3348-3354

Giles FJ, Kantarjian HM, Bekele BN, Cortes JE, Faderl S, Thomas DA, Manshouri T, Rogers A, Keating MJ, Talpaz M, O’Brien S, Albitar M (2002) Bone marrow cyclooxygenase-2 levels are elevated in chronicphase chronic myeloid leukaemia and are associated with reduced survival. Br J Haematol 119(1): 38-45

Gorre ME, Mohammed M, Ellwood K, Hsu N, Paquette R, Nagesh Rao P, Sawyers CL (2001) Clinical resistance to STI-571 cancer therapy caused by BCR-ABL gene mutation or amplification. Science 293(5531): 876-880

Hiwase DK, Saunders V, Hewett D, Frede A, Zrim S, Dang P, Eadie L, To LB, Melo J, Kumar S, Hughes TP, White DL (2008) Dasatinib cellular uptake and efflux in chronic myeloid leukemia cells: therapeutic implications. Clin Cancer Res 14(12): 3881-3888

Holle SK, Ciarimboli G, Edemir B, Neugebauer U, Pavenstädt H, Schlatter E (2011) Properties and regulation of organic cation transport in freshly isolated mouse proximal tubules analyzed with a fluorescence reader-based method. Pflugers Archiv Eur J Physiol 462(2): 359-369

Honjo H, Uwai Y, Aoki Y, Iwamoto K (2011) Stereoselective inhibitory effect of flurbiprofen, ibuprofen and naproxen on human organic anion transporters hOAT1 and hOAT3. Biopharm Drug Dispos 32(9): 518-524

Hughes T, Deininger M, Hochhaus A, Branford S, Radich J, Kaeda J, Baccarani M, Cortes J, Cross NCP, Druker BJ, Gabert J, Grimwade D, Hehlmann R, Kamel-Reid S, Lipton JH, Longtine J, Martinelli G, Saglio G, Soverini S, Stock W, Goldman JM (2006) Monitoring CML patients responding to treatment with tyrosine kinase inhibitors: Review and recommendations for harmonizing current methodology for detecting BCR-ABL transcripts and kinase domain mutations and for expressing results. Blood 108(1): 28-37

Hughes TP, Branford S, White DL, Reynolds J, Koelmeyer R, Seymour JF, Taylor K, Arthur C, Schwarer A, Morton J, Cooney J, Leahy MF, Rowlings P, Catalano J, Hertzberg M, Filshie R, Mills AK, Fay K, Durrant S, Januszewicz H, Joske D, Underhill C, Dunkley S, Lynch K, Grigg A (2008) Impact of early dose intensity on cytogenetic and molecular responses in chronicphase CMLpatients receiving $600 \mathrm{mg} / \mathrm{day}$ of imatinib as initial therapy. Blood 112(10): 3965-3973

Hughes TP, Hochhaus A, Branford S, Müller MC, Kaeda JS, Foroni L, Druker BJ, Guilhot F, Larson RA, O’Brien SG, Rudoltz MS, Mone M, Wehrle E, Modur V, Goldman JM, Radich JP (2010) Long-term prognostic significance of early molecular response to imatinib in newly diagnosed chronic myeloid leukemia: An analysis from the International Randomized Study of Interferon and STI571 (IRIS). Blood 116(19): 3758-3765

Juhlin T, Björkman S, Gunnarsson B, Fyge A, Roth B, Höglund P (2004) Acute administration of diclofenac, but possibly not long term low dose aspirin, causes detrimental renal effects in heart failure patients treated with ACE-inhibitors. Eur J Heart Fail 6(7): 909-916

Jung N, Lehmann C, Rubbert A, Knispel M, Hartmann P, van Lunzen J, Stellbrink HJ, Faetkenheuer G, Taubert D (2008) Relevance of the organic cation transporters 1 and 2 for antiretroviral drug therapy in human immunodeficiency virus infection. Drug Metab Dispos 36(8): 1616-1623

Kalle AM, Sachchidanand S, Pallu R (2010) Bcr-Abl-independent mechanism of resistance to imatinib in K562 cells: Induction of cyclooxygenase-2 (COX-2) by histone deacetylases (HDACs). Leuk Res 34(9): 1132-1138

Khamdang S, Takeda M, Noshiro R, Narikawa S, Enomoto A, Anzai N, Piyachaturawat P, Endou $H$ (2002) Interactions of human organic anion transporters and human organic cation transporters with nonsteroidal anti-inflammatory drugs. J Pharmacol Exp Ther 303(2): 534-539
Kindla J, Fromm MF, Konig J (2009) In vitro evidence for the role of OATP and OCT uptake transporters in drug-drug interactions. Expert Opin Drug Metab Toxicol 5(5): 489-500

Minematsu T, Giacomini KM (2011) Interactions of Tyrosine Kinase Inhibitors with Organic Cation Transporters, OCTs, and Multidrug and Toxic Compound Extrusion Proteins, MATEs. Mol Cancer Ther 10(3): 531-539

Mulato AS, Ho ES, Cihlar T (2000) Nonsteroidal anti-inflammatory drugs efficiently reduce the transport and cytotoxicity of adefovir mediated by the human renal organic anion transporter 1. J Pharmacol Exp Ther 295(1): 10-15

Nozaki Y, Kusuhara H, Endou H, Sugiyama Y (2004) Quantitative evaluation of the drug-drug interactions between methotrexate and nonsteroidal anti-inflammatory drugs in the renal uptake process based on the contribution of organic anion transporters and reduced folate carrier. J Pharmacol Exp Ther 309(1): 226-234

Perneger TV, Whelton PK, Klag MJ (1994) Risk of kidney failure associated with the use of acetaminophen, aspirin, and nonsteroidal antiinflammatory drugs. $N$ Engl J Med 331(25): 1675-1679

Rich SA (2001) The coxibs, selective inhibitors of cyclooxygenase-2. N Engl $J$ Med 345(23): 1709

Shah NP, Nicoll JM, Nagar B, Gorre ME, Paquette RL, Kuriyan J, Sawyers CL (2002) Multiple BCR-ABL kinase domain mutations confer polyclonal resistance to the tyrosine kinase inhibitor imatinib (STI571) in chronic phase and blast crisis chronic myeloid leukemia. Cancer Cell 2(2): 117-125

Siu SSN, Yeung JHK, Lau TK (2000) A study on placental transfer of diclofenac in first trimester of human pregnancy. Hum Reprod 15(11): 2423-2425

Subhashini J, Mahipal SVK, Reddanna P (2005) Anti-proliferative and apoptotic effects of celecoxib on human chronic myeloid leukemia in vitro. Cancer Lett 224(1): 31-43

Thomas J, Wang L, Clark RE, Pirmohamed M (2004) Active transport of imatinib into and out of cells: Implications for drug resistance. Blood 104(12): 3739-3745

Ulrich CM, Bigler J, Potter JD (2006) Non-steroidal anti-inflammatory drugs for cancer prevention: Promise, perils and pharmacogenetics. Nat Rev Cancer 6(2): 130-140

Umehara KI, Iwatsubo T, Noguchi K, Usui T, Kamimura H (2008) Effect of cationic drugs on the transporting activity of human and rat OCT/Oct 1-3 in vitro and implications for drug-drug interactions. Xenobiotica 38(9): 1203-1218

White D, Saunders V, Grigg A, Arthur C, Filshie R, Leahy MF, Lynch K, To LB, Hughes $\mathrm{T}$ (2007a) Measurement of in vivo BCR-ABL kinase inhibition to monitor imatinib-induced target blockade and predict response in chronic myeloid leukemia. J Clin Oncol 25(28): 4445-4451

White D, Saunders V, Lyons AB, Branford S, Grigg A, To LB, Hughes T (2005) In vitro sensitivity to imatinib-induced inhibition of ABL kinase activity is predictive of molecular response in patients with de novo CML. Blood 106(7): 2520-2526

White DL, Dang P, Engler J, Frede A, Zrim S, Osborn M, Saunders VA, Manley PW, Hughes TP (2010) Functional activity of the OCT-1 protein is predictive of long-term outcome in patients with chronic-phase chronic myeloid leukemia treated with imatinib. J Clin Oncol 28(16): 2761-2767

White DL, Hughes TP (2012) Classification of Patients With Chronic Myeloid Leukemia on Basis of BCR-ABL Transcript Level at 3 Month Fails to Identify Patients With Low Organic Cation Transporter-1 Activity Destined to Have Poor Imatinib Response. J Clin Oncol 30(10): 1144-1145

White DL, Saunders VA, Dang P, Engler J, Venables A, Zrim S, Zannettino A, Lynch K, Manley PW, Hughes T (2007b) Most CML patients who have a suboptimal response to imatinib have low OCT-1 activity: higher doses of imatinib may overcome the negative impact of low OCT-1 activity. Blood 110(12): 4064-4072

White DL, Saunders VA, Dang P, Engler J, Zannettino ACW, Cambareri AC Quinn SR, Manley PW, Hughes TP (2006) OCT-1-mediated influx is a key determinant of the intracellular uptake of imatinib but not nilotinib (AMN107): Reduced OCT-1 activity is the cause of low in vitro sensitivity to imatinib. Blood 108(2): 697-704

This work is published under the standard license to publish agreement. After 12 months the work will become freely available and the license terms will switch to a Creative Commons Attribution-NonCommercial-Share Alike 3.0 Unported License. 